\title{
Haplotype Association of the MAP2K5 Gene with Antipsychotics-Induced Symptoms of Restless Legs Syndrome among Patients with Schizophrenia
}

\author{
Seung-Gul Kang1, Yu Jin Lee², Young-Min Park ${ }^{3}$, Leen Kim4, and Heon-Jeong Lee ${ }^{4 凶}$ \\ 'Department of Psychiatry, Gil Medical Center, Gachon University School of Medicine, Incheon, Republic of Korea \\ ${ }^{2}$ Department of Psychiatry, Seoul National University College of Medicine, Seoul, Republic of Korea \\ ${ }^{3}$ Department of Psychiatry, Ilsan Paik Hospital, Inje University College of Medicine, Goyang, Republic of Korea \\ ${ }^{4}$ Department of Psychiatry, Korea University College of Medicine, Seoul, Republic of Korea
}

\begin{abstract}
Objective Restless legs syndrome (RLS) is considered a genetic disease and, following a genome-wide association study conducted in 2007, the mitogen-activated protein kinase 5 (MAP2K5) gene has been regarded as the promising candidate gene for RLS. The present study investigated whether polymorphisms of MAP2K5 are associated with antipsychotics-induced RLS in schizophrenia.

Methods We assessed antipsychotics-induced RLS symptoms in 190 Korean schizophrenic patients using the diagnostic criteria of the International Restless Legs Syndrome Study Group. Five single-nucleotide polymorphisms (SNPs) of MAP2K5 were genotyped. We investigated genetic and haplotypic associations of these five SNPs with the risk of antipsychotics-induced RLS symptoms.

Results We divided the 190 subjects into 2 groups: 1) those with RLS symptoms ( $\mathrm{n}=96)$ and 2 ) those without RLS symptoms ( $\mathrm{n}=94$ ). There were no significant intergroup differences in the distributions of the genotypes and alleles of the rs1026732, rs11635424, rs12593813, rs4489954, and rs3784709 SNPs. However, the haplotype analysis showed that the G-G-G-G-T (rs1026732-rs11635424rs12593813-rs4489954-rs3784709) haplotype was associated with RLS symptoms (permutation $\mathrm{p}=0.033$ ).

Conclusion These data suggest that a haplotype of MAP2K5 polymorphisms confers increased susceptibility to antipsychotics-induced RLS symptoms in schizophrenic patients.

Psychiatry Investig 2018;15(1):84-89
\end{abstract}

Key Words Restless legs syndrome, Antipsychotics, Schizophrenia, MAP2K5, Polymorphism, Haplotype.

\section{INTRODUCTION}

Restless legs syndrome (RLS) is a sleep disorder whose prevalence varies depending on the populations analyzed and methods applied. However, it is generally reported that $2-3 \%$ of the population suffers from RLS, which indicates the importance of appropriate treatment. ${ }^{1}$ Typical clinical manifestations of RLS include uncomfortable sensations in the legs and irresistible urges to move the legs, and these symptoms aggravate or start at night and are temporarily relieved by leg movements.

Received: January 23, 2017 Revised: March 21, 2017

Accepted: April 9, 2017 Available online: October 17, 2017

$\bowtie$ Correspondence: Heon-Jeong Lee, MD, PhD

Department of Psychiatry, Anam Hospital, Korea University College of Medicine, 73 Inchon-ro, Seongbuk-gu, Seoul 02841, Republic of Korea

Tel: +82-2-920-6721, Fax: +82-2-929-7679, E-mail: leehjeong@korea.ac.kr

(a) This is an Open Access article distributed under the terms of the Creative Commons Attribution Non-Commercial License (http://creativecommons.org/licenses/bync/4.0) which permits unrestricted non-commercial use, distribution, and reproduction in any medium, provided the original work is properly cited.
Many etiologies have been reported for RLS, and they can be classified into idiopathic and secondary RLS. Secondary RLS is attributable to factors such as iron deficiency, renal failure, pregnancy, neuropathy, and certain medications, especially those involving the dopamine receptor. ${ }^{2}$ Antipsychotics are common causes of secondary RLS, and it was previously found that the incidence of RLS was twofold higher in schizophrenia patients than in healthy controls, which is probably attributable to the use of antipsychotics. ${ }^{3,4}$

The pathophysiology of idiopathic RLS has not been fully explained before. However, it is known that genetic factors and central dopaminergic dysfunction are important causes of idiopathic RLS. Approximately half of RLS patients are known to have a family history of RLS, ${ }^{5}$ and nine genetic loci (2q, 4q, $9 \mathrm{p}, 12 \mathrm{q}, 14 \mathrm{q}, 16 \mathrm{p}, 17 \mathrm{p}, 19 \mathrm{p}$, and 20p) for RLS have been reported based on linkage analysis. ${ }^{5-12}$ In addition, two independent genome-wide association studies (GWASs) found new candidate genes such as the mitogen-activated protein kinase 
5 (MAP2K5) gene, BTB (POZ) domain-containing 9 (BTBD9) gene, intronic variants of the Meis homeobox 1 (MEIS1) gene, LBXCOR1, glyoxalase I (GLO1) gene, and dynein axonemal heavy chain (DNAH8) gene for RLS, which had not previously been considered. ${ }^{13,14}$ Six single-nucleotide polymorphisms (SNP) of MAP2K5 within the region of $15 \mathrm{q}$ have been shown to be significantly associated with RLS. ${ }^{14}$

Antipsychotics-induced RLS might have a similar genetic etiology to idiopathic RLS. Only some of the schizophrenic patients who take antipsychotics develop RLS symptoms. It has been hypothesized that the occurrence of antipsychoticsinduced RLS is related to differences in the genetic vulnerability to RLS, and the association between antipsychotics-induced RLS and several candidate genes has been investigated based on this hypothesis. ${ }^{15-21}$ Although MAP2K5 is one of the most promising candidate genes in GWASs, ${ }^{14}$ no study has performed a genetic association and haplotype analysis with antipsychotics-induced RLS.

The aim of this study was to determine whether MAP2K5 and haplotypes of this gene are associated with the core symptoms of antipsychotics-induced RLS in schizophrenia.

\section{METHODS}

\section{Subjects}

In total, 190 Korean patients with schizophrenia were enrolled from Korea University Hospital and three collaborating hospitals. All of the subjects had been diagnosed with schizophrenia by board-certified psychiatrists based on the Korean version of the Structured Clinical Interview for DSMIV and had taken antipsychotic medications. ${ }^{22}$ The dose of neuroleptics was converted into chlorpromazine equivalents pursuant to the standard guidelines and previous studies. ${ }^{23-27}$ This study was approved by the Institutional Review Board (IRB) of Korea University Medical Center (IRB NO. IEC07014), and all of the subjects provided written informed consent to participate after the study has been explained to them. Patients consistent with the following exclusion criteria were excluded: 1) presence of other Axis I diagnoses except schizophrenia, mental retardation, a history of substance abuse or dependence including alcohol, or a neurological disorder or brain injury, 2) serious medical diseases or other conditions that are similar to RLS symptoms (e.g., anemia, renal failure, or peripheral neuropathy), or 3) severe psychosis or agitation that prevented participation in an interview. The characteristics of schizophrenia patients with antipsychotics-induced RLS have been reported previously, ${ }^{3}$ as have other findings for such subjects. $^{15-21}$

\section{Assessment of RLS}

RLS was assessed by a board-certified psychiatrist based on the diagnostic criteria of the International Restless Legs Syndrome Study Group (IRLSSG). ${ }^{28}$ The following specific items are addressed by these criteria: 1) urge to move the legs, 2) unpleasant sensations in the legs, 3) urge to move or unpleasant sensations in the legs worsening during rest and relieved by movements, and 4) urge to move the legs or unpleasant sensations that worsened or occurred only during the evening or nighttime. In order to obtain an adequate and similar sample size in both the case and control groups for the genetic association study, we divided the subjects into the following two groups: (a) subjects who met either criterion 1) or 2) of the IRLSSG diagnostic criteria (i.e., core symptoms of RLS) and (b) subjects without RLS symptoms. The RLS severity was determined using the IRLSSG rating scale for RLS. ${ }^{29}$ We did not consider cases as RLS symptoms when the discomfort in the legs was caused by neuropathy, arthritis, peripheral vascular disease, leg cramps, psychotic agitation, or tactile hallucination. The presence and severity of antipsychotics-induced akathisia were assessed using the Barnes Akathisia Rating Scale (BARS). ${ }^{30}$ Akathisia was determined as being present in the case where the Barnes Global Score was $\geq 2 .^{30}$

\section{DNA analysis and genotyping}

We selected the following five SNPs of MAP2K5 as candidate genes in this study: rs1026732, rs11635424, rs12593813, rs4489954, and rs3784709. These constituted five of the six SNPs that have shown significant associations in previous GWAS research; rs6494696 was excluded, which is within the intergenic region of LBXCOR1. The genomic DNA was extracted from the whole blood using the Accuprep Genomic DNA Extraction Kit (Bioneer, Daejeon, Korea). The genotyping was performed using high-resolution melting-curve analysis. Polymerase chain reactions (PCRs) were performed in a volume of $20 \mu \mathrm{L}$ per reaction in the 96-well Bio-Rad CFX96 Real Time PCR System (Bio-Rad, Hercules, CA, USA). The five SNPs of MAP2K5 (rs1026732, rs11635424, rs12593813, rs4489954, and rs3784709) were genotyped using a previously described method: ${ }^{14,31}$ their missing genotype rates were 1.6, 1.6, 6.3, 1.6, and $2.1 \%$, respectively.

\section{Statistical analysis}

Conformity with Hardy-Weinberg equilibrium (HWE) was tested based on the $\chi^{2}$ test for goodness of fit; this test was also used to analyze categorical data ver. 23.0 (SPSS Inc., Chicago, IL, USA). These statistical analyses were performed using SPSS for Windows. The cutoff for statistical significance was set at $\mathrm{p}<0.05$; however, after applying the Bonferroni correction, the cutoff was set at $\mathrm{p}<0.01$ in Tables 1 and 2 (since five 
SNPs were genotyped in this study). The linkage disequilibrium (LD) and haplotype analyses between the RLS-symptoms group and no-RLS-symptoms group were conducted using SNPAlyze (version 7, DYNACOM, Chiba, Japan), which was established based on the expectation-maximization algorithm and the maximum-likelihood approach.

\section{RESULTS}

\section{Demographic and clinical characteristics of participants}

The participants were aged 39.6 \pm 9.2 years (mean $\pm S D$, range 22-66 years) and they comprised 106 (55.8\%) males and 84 (44.2\%) females. All participants were diagnosed as schizophrenia and 44 (23.2\%) of them met the IRLSSG diagnostic criteria. The participants were classified into a group with core RLS symptoms ( $\mathrm{n}=96,50.5 \%)$ and another without core RLS symptoms ( $n=94,49.5 \%)$. Since the RLS symptoms are similar to those of akathisia, 16 RLS patients could also be diagnosed as having akathisia based on the BARS. We did not exclude them from the RLS group only because they met the diagnostic criteria of akathisia. That is the reason that the antipsychotics-induced RLS and akathisia could be comorbid with each other and might share the common pathogenesis. We concluded that excluding such subjects just because they met the diagnostic criteria of akathisia could result in another bias.

The number of subjects taking one, two, and three antipsychotics was 121,63 , and 6 , respectively. The five medications most frequently used as main neuroleptics were risperidone, clozapine, haloperidol, sulpiride, and olanzapine (in the order of the frequency). The range of the chlorpromazine equivalent of antipsychotics was 100 to $3400 \mathrm{mg}$ /day and the mean \pm standard deviation of chlorpromazine equivalent was $524.3 \pm$ $451.0 \mathrm{mg} /$ day.

\section{rs1026732, rs11635424, rs12593813, rs4489954, and rs3784709 SNPs of MAP2K5}

The genotype frequencies did not deviate from HWE for all six SNPs: $r s 102673\left(\chi^{2}=0.428, \mathrm{p}=0.5131\right), \operatorname{rs} 11635424\left(\chi^{2}=\right.$ $0.268, \mathrm{p}=0.6049), \mathrm{rs} 12593813\left(\chi^{2}=0.477, \mathrm{p}=0.4899\right), \mathrm{rs} 4489954$ $\left(\chi^{2}=0.177, \mathrm{p}=0.6742\right)$, and $\mathrm{rs} 3784709\left(\chi^{2}=0.547, \mathrm{p}=0.4594\right)$. The genotype frequency in the additive models did not show any statistically significant difference in the five SNPs: rs 1026732 $\left(\chi^{2}=2.158, \mathrm{p}=0.0340\right), \mathrm{rs} 11635424\left(\chi^{2}=2.100, \mathrm{p}=0.350\right), \mathrm{rs} 12593813$ $\left(\chi^{2}=2.659, \mathrm{p}=0.265\right), \mathrm{rs} 4489954\left(\chi^{2}=1.579, \mathrm{p}=0.454\right)$, and rs3784709 $\left(\chi^{2}=1.265, \mathrm{p}=0.531\right)$ (Table 1$)$. There was also no

Table 1. Results of a genotype association analysis between RLS symptoms in schizophrenia and five SNPs of the MAP2K5 gene

\begin{tabular}{|c|c|c|c|c|c|c|c|}
\hline \multirow{2}{*}{ SNP } & \multicolumn{3}{|c|}{ Genotype frequency } & \multicolumn{4}{|c|}{ Genotype association analysis } \\
\hline & Genotype & RLS symptoms $(\mathrm{N}=96)$ & No RLS symptom $(\mathrm{N}=94)$ & Model & $\chi^{2}$ & $\mathrm{p}$ & OR $(95 \% \mathrm{CI})$ \\
\hline \multirow[t]{4}{*}{ rs1026732 } & AA & $50(53.2 \%)$ & $40(43.0 \%)$ & Dominant & 0.001 & 0.980 & $1.01(0.40-2.56)$ \\
\hline & AG & $34(36.2 \%)$ & $43(46.2 \%)$ & Heterozygous & 1.956 & 0.162 & $0.66(0.37-1.18)$ \\
\hline & GG & $10(10.6 \%)$ & $10(10.8 \%)$ & Recessive & 1.941 & 0.164 & $0.66(0.37-1.18)$ \\
\hline & & & & Additive & 2.158 & 0.340 & \\
\hline \multirow[t]{4}{*}{ rs11635424 } & AA & $42(44.2 \%)$ & $32(34.8 \%)$ & Dominant & 0.012 & 0.914 & $0.96(0.43-2.11)$ \\
\hline & AG & $38(40.0 \%)$ & $46(50.0 \%)$ & Heterozygous & 1.889 & 0.169 & $0.67(0.37-1.19)$ \\
\hline & GG & $15(15.8 \%)$ & $14(15.2 \%)$ & Recessive & 1.737 & 0.187 & $0.67(0.37-1.21)$ \\
\hline & & & & Additive & 2.100 & 0.350 & \\
\hline \multirow[t]{4}{*}{ rs12593813 } & AA & $41(45.1 \%)$ & $31(35.6 \%)$ & Dominant & 0.250 & 0.617 & $0.81(0.36-1.85)$ \\
\hline & AG & $35(38.5 \%)$ & $44(50.6 \%)$ & Heterozygous & 2.644 & 0.104 & $0.61(0.34-1.11)$ \\
\hline & GG & $15(16.5 \%)$ & $12(13.8 \%)$ & Recessive & 1.639 & 0.200 & $0.68(0.37-1.23)$ \\
\hline & & & & Additive & 2.659 & 0.265 & \\
\hline \multirow[t]{4}{*}{ rs4489954 } & GG & $10(10.6 \%)$ & $9(9.7 \%)$ & Dominant & 0.047 & 0.828 & $0.90(0.35-2.33)$ \\
\hline & GT & $35(37.2 \%)$ & $43(46.2 \%)$ & Heterozygous & 1.558 & 0.212 & $0.69(0.39-1.24)$ \\
\hline & $\mathrm{TT}$ & $49(52.1 \%)$ & $41(44.1 \%)$ & Recessive & 1.211 & 0.271 & $0.72(0.41-1.29)$ \\
\hline & & & & Additive & 1.579 & 0.454 & \\
\hline \multirow[t]{4}{*}{ rs3784709 } & $\mathrm{CC}$ & $14(14.9 \%)$ & $9(9.8 \%)$ & Dominant & 1.121 & 0.290 & $0.62(0.25-1.51)$ \\
\hline & CT & $39(41.5 \%)$ & $38(41.3 \%)$ & Heterozygous & 0.001 & 0.980 & $1.01(0.56-1.81)$ \\
\hline & $\mathrm{TT}$ & $41(43.6 \%)$ & 45 (48.9\%) & Recessive & 0.525 & 0.469 & $1.24(0.70-2.21)$ \\
\hline & & & & Additive & 1.265 & 0.531 & \\
\hline
\end{tabular}

RLS: restless legs syndrome, SNPs: single-nucleotide polymorphisms, MAP2K5: mitogen-activated protein kinase 5, OR: odds ratio, CI: confidence interval 
Table 2. Results of an allele association analysis between RLS symptoms in schizophrenia and five SNPs of MAP2K5

\begin{tabular}{lcccccc}
\hline \multirow{2}{*}{ SNP } & MAF (RLS symptoms) & MAF (no RLS symptoms) & \multirow{2}{*}{ Risk allele } & \multicolumn{3}{c}{ Allele association analysis } \\
\cline { 5 - 7 } & & & & $\chi^{2}$ & $\mathrm{p}$ & OR (95\% CI) \\
\hline rs1026732 & 0.287 & 0.339 & N/A & 1.152 & 0.283 & $1.27(0.82-1.97)$ \\
rs11635424 & 0.358 & 0.402 & N/A & 0.778 & 0.378 & $1.21(0.80-1.83)$ \\
rs12593813 & 0.357 & 0.391 & N/A & 0.431 & 0.512 & $1.16(0.75-1.78)$ \\
rs4489954 & 0.293 & 0.328 & N/A & 0.548 & 0.459 & $0.85(0.55-1.31)$ \\
rs3784709 & 0.356 & 0.304 & N/A & 1.138 & 0.286 & $1.27(0.82-1.95)$ \\
\hline
\end{tabular}

MAF: minor allele frequency, N/A: not applicable, RLS: restless legs syndrome, SNPs: single-nucleotide polymorphisms, MAP2K5: mitogenactivated protein kinase 5, OR: odds ratio, CI: confidence interval

Table 3. Estimated haplotype frequencies of MAP2K5 rs1026732-rs11635424-rs12593813-rs4489954-rs3784709 and the association significance

\begin{tabular}{cccccc}
\hline \multirow{2}{*}{$\begin{array}{c}\text { Haplotype (rs1026732-rs11635424- } \\
\text { rs12593813-rs4489954-rs3784709) }\end{array}$} & $\begin{array}{c}\text { Overall } \\
\text { permutation } \mathrm{p}\end{array}$ & Overall & RLS symptoms & No RLS symptoms & Permutation $\mathrm{p}$ \\
\cline { 3 - 5 } A-A-A-T-T & 0.581 & 0.4890 & 0.5095 & 0.4670 & 0.380 \\
G-G-G-G-C & & 0.1726 & 0.1920 & 0.1521 & 0.448 \\
G-G-G-G-T & & 0.1310 & 0.0936 & 0.1698 & $0.033^{*}$ \\
A-A-A-T-C & & 0.1270 & 0.1188 & 0.1365 & 0.656 \\
\hline
\end{tabular}

Only common haplotypes (frequency $>5 \%$ ) are listed. *significant $\mathrm{p}$ value $(\mathrm{p}<0.05)$

Table 4. Linkage disequilibrium coefficients $\left(D^{\prime}\right.$ and $\left.r^{2}\right)$ and $p$ values among the MAP2K5 polymorphisms

\begin{tabular}{|c|c|c|c|c|c|}
\hline $\mathrm{D}^{\prime} \quad \mathrm{r}^{2}, \mathrm{p}$ value & rs1026732 & rs11635424 & rs12593813 & rs4489954 & rs3784709 \\
\hline rs1026732 & - & $0.6673,5.139 \times 10^{-56}$ & $0.6804,1.11 \times 10^{-54}$ & $0.9874,5.214 \times 10^{-81}$ & $0.0825,3.49 \times 10^{-8}$ \\
\hline rs11635424 & 0.9545 & - & $1,2.092 \times 10^{-79}$ & $0.686,4.269 \times 10^{-57}$ & $0.0818,5.04 \times 10^{-8}$ \\
\hline rs12593813 & 0.953 & 1 & - & $0.6941,6.395 \times 10^{-56}$ & $0.1039,1.65 \times 10^{-9}$ \\
\hline rs4489954 & 1 & 0.9693 & 0.9686 & - & $0.0883,6.00 \times 0^{-9}$ \\
\hline rs3784709 & 0.3 & 0.3128 & 0.3561 & 0.3067 & - \\
\hline
\end{tabular}

MAP2K5: mitogen-activated protein kinase 5

statistically significant difference in dominant, recessive, and heterozygous models (Table 1). The allele frequencies of the five SNPS did not differ significantly between the two groups: $\operatorname{rs} 1026732\left(\chi^{2}=1.152, \mathrm{p}=0.283\right), \operatorname{rs} 11635424\left(\chi^{2}=0.778, \mathrm{p}=0.378\right)$, $\operatorname{rs} 12593813\left(\chi^{2}=0.431, \mathrm{p}=0.512\right), \mathrm{rs} 4489954\left(\chi^{2}=0.548, \mathrm{p}=0.459\right)$, and $\operatorname{rs} 3784709\left(\chi^{2}=1.138, \mathrm{p}=0.286\right)$ (Table 2$)$.

\section{Haplotype and LD analyses}

The haplotype analysis (Table 3) revealed that the G-G-GG-T (rs1026732-rs11635424-rs12593813-rs4489954-rs3784709) haplotype was associated with RLS symptoms (permutation $\mathrm{p}=0.033$ ). The G-A-A-T-C haplotype was also associated with RLS symptoms (permutation $\mathrm{p}<0.001$ ), but this is not included in Table 3 since it is not a common haplotype (i.e., frequency $<5 \%)$. The pairwise LD values including the $\mathrm{D}^{\prime}, \mathrm{r}^{2}$, and $\mathrm{p}$ values for consecutive SNPs are listed in Table 4.

\section{DISCUSSION}

Up to $80 \%$ of the schizophrenia patients experience sleep problems and many of them suffer from RLS, which impairs their physical and mental health. ${ }^{32}$ Our previous study revealed that inpatient schizophrenia patients showed that the frequency of RLS was double in the schizophrenia group (21.4\%) compared to healthy controls (9.3\%) and RLS symptoms was associated with more severe insomnia and psychiatric symptoms. ${ }^{3}$ Since the antipsychotic-induced RLS in schizophrenia is considered as being more common and clinically important than before, we believe that the pharmacogenetic study on promising candidate genes in this topic has clinical and scientific merits.

This study found no significant associations between 1) the genotypes and alleles of the rs1026732, rs11635424, rs12593813, rs4489954, and rs3784709 SNPs of MAP2K5 and 2) antipsychotics-induced RLS symptoms. However, the haplotype anal- 
ysis showed that a haplotype of the MAP2K5 polymorphisms confers increased susceptibility to antipsychotics-induced RLS symptoms in schizophrenic patients. The rs1026732-rs11635424rs12593813-rs4489954-rs3784709 haplotype analysis showed a significant association of G-G-G-G-T and G-A-A-T-C with a low risk of developing antipsychotics-induced RLS symptoms. To the best of our knowledge, this is the first report of positive findings in a haplotype analysis of MAP2K5 with RLS; note that previous studies of MEIS1 have also shown positive findings in haplotype analyses. ${ }^{14,33}$

Schizophrenia patients frequently suffer from side effects of neuroleptic-induced RLS, but the pathophysiology is not fully understood. Nevertheless, we assumed that the etiology of neuroleptic-induced RLS could be similar to that of idiopathic RLS. Since idiopathic RLS has shown novel and strongly significant findings in GWASs and replication studies, ${ }^{14,34,35}$ we aimed to replicate in our sample the significant association of MAP2K5, a promising candidate gene, with antipsychoticsinduced RLS symptoms.

MAP2K5 is a dual specificity protein kinase that belongs to the MAP kinase family and activates MAPK7/extracellular-signal-regulated kinase 5 (ERK5), interacting therewith. ${ }^{36}$ MAP2K5 and ERK5 are expressed abundantly in heart and skeletal muscles, and the MAP2K5/ERK5 MAP kinase cascade is critical at the early stage of muscle cell differentiation and is known to be important in the neuroprotection of dopaminergic neurons. ${ }^{14,37,38}$ Impairment of the dopamine system is believed to be one of the important etiologies of RLS, and dopaminergic D2/D3 agonists have been used as treatments of idiopathic RLS. ${ }^{39}$ In addition, MAP kinases regulate $L B X C O R 1$ and, since LBXCOR1 is expressed in a subset of dorsal horn interneurons of the developing spinal cord, MAP kinases are likely to be involved in the modulation of pain and sensory inputs. ${ }^{40}$

Winkelman et al. ${ }^{14}$ conducted a GWAS of 500,568 SNPs using an Affymetrix 500K array set and reported in 2007 that SNPs of MAP2K5 are closely associated with RLS. However, some subsequent replication studies of MAP2K5 have resulted in different conclusions. Yang et al. ${ }^{35}$ performed a familybased and population-based case-control study involving a US population, and selected only the rs 1026732 polymorphism, which had been found to have the most significant association with RLS in the previous GWAS. Winkelman et al. ${ }^{41}$ also performed an enlarged GWAS involving 922 RLS patients and 1,526 control cases, and conducted a replication study with independent case-control samples in order to confirm the previous research and identify risk loci, and reported a significant result for the rs1259813 SNP of MAP2K5. Another study involving 244 RLS patients (including 123 patients with a family history) and a control group of 497 subjects examined 11 candidate SNPs, and found no association in MAP2K5 and an insignificant trend in rs6494696 ( $\mathrm{p}=0.05)$ in familial RLS patients. ${ }^{42}$ The patients in that study with a family history showed a stronger association than sporadic RLS patients in cases of MEIS1 and BTBD9, which was attributed to environmental and genetic factors in sporadic RLS. ${ }^{42} \mathrm{~A}$ recent Korean replication study of idiopathic RLS also found no significant relationship. ${ }^{43}$ These diverse research results may have due to differences in the method used to diagnose RLS and thus differences in RLS phenotypes ${ }^{40}$ and racial differences in genotype and allele frequencies. Racial differences are important in MAP2K5, since RLS-associated alleles are significantly less frequent in Asians ${ }^{40}$ and the minor allele of the $\mathrm{Eu}$ ropean ancestry is opposite to that of Asians (Chinese and Japanese) in rs1026732 (refer to dbSNP: http://www.ncbi.nlm. nih.gov/projects/SNP/). In addition, the present study may have been affected by many factors other than genetic ones since it adopted antipsychotics-induced RLS as its phenotype.

This study had several limitations. First, the sample was relatively small for investigating genetic associations, especially considering current genetic research trends. Second, various types of antipsychotics were taken by the subjects. It will be necessary to perform a similar study of subjects taking identical or consistent antipsychotics in order to fully understand the association between promising candidate genes such as MAP2K5 and antipsychotics-induced RLS. Moreover, future studies are also needed to evaluate the association between RLS and other candidate genes for primary RLS such as GLO1 and DNAH8. Such studies will provide a better understanding of the etiologies of antipsychotics-induced and idiopathic RLS, and also help clinicians to select the safest antipsychotics for different patients.

\section{Acknowledgments}

This study was supported by the Otsuka schizophrenia research fund for the young investigator of the Korea Society for Schizophrenia Research.

\section{REFERENCES}

1. Phillips B, Young T, Finn L, Asher K, Hening WA, Purvis C. Epidemiology of restless legs symptoms in adults. Arch Intern Med 2000;160: 2137-2141.

2. Oka Y, Ioue Y. Secondary restless legs syndrome. Brain Nerve 2009;61: 539-547.

3. Kang SG, Lee HJ, Jung SW, Cho SN, Han C, Kim YK, et al. Characteristics and clinical correlates of restless legs syndrome in schizophrenia. Prog Neuropsychopharmacol Biol Psychiatry 2007;31:1078-1083.

4. Aggarwal S, Dodd S, Berk M. Restless leg syndrome associated with atypical antipsychotics: current status, pathophysiology, and clinical implications. Curr Drug Saf 2015;10:98-105.

5. Winkelman JW, Plante DT. Foundations of Psychiatric Sleep Medicine. New York: Cambridge University Press, Cambridge; 2010.

6. Pichler I, Marroni F, Volpato CB, Gusella JF, Klein C, Casari G, et al. Linkage analysis identifies a novel locus for restless legs syndrome on chromosome 2q in a South Tyrolean population isolate. Am J Hum Genet 2006;79:716-723. 
7. Chen S, Ondo WG, Rao S, Li L, Chen Q, Wang Q. Genomewide linkage scan identifies a novel susceptibility locus for RLS on chromosome 9p. Am J Hum Genet 2004;74:876-885.

8. Desautels A, Turecki G, Montplaisir J, Xiong L, Walters AS, Ehrenberg $\mathrm{BL}$, et al. Restless legs syndrome: confirmation of linkage to chromosome 12q, genetic heterogeneity, and evidence of complexity. Arch Neurol 2005;62:591-596.

9. Levchenko A, Montplaisir JY, Dube MP, Riviere JB, St-Onge J, Turecki $\mathrm{G}$, et al. The $14 \mathrm{q}$ restless legs syndrome locus in the French Canadian population. Ann Neurol 2004;55:887-891.

10. Kemlink D, Plazzi G, Vetrugno R, Provini F, Polo O, Stiasny-Kolster K, et al. Suggestive evidence for linkage for restless legs syndrome on chromosome 19p13. Neurogenetics 2008;9:75-82.

11. Levchenko A, Provost S, Montplaisir JY, Xiong L, St-Onge J, Thibodeau $\mathrm{P}$, et al. A novel autosomal dominant restless legs syndrome locus maps to chromosome 20p13. Neurology 2006;67:900-901.

12. Levchenko A, Montplaisir JY, Asselin G, Provost S, Girard SL, Xiong L, et al. Autosomal-dominant locus for Restless Legs Syndrome in FrenchCanadians on chromosome 16p12.1. Mov Disord 2009;24:40-50.

13. Stefansson H, Rye DB, Hicks A, Petursson H, Ingason A, Thorgeirsson TE, et al. A genetic risk factor for periodic limb movements in sleep. N Engl J Med 2007;357:639-647.

14. Winkelmann J, Schormair B, Lichtner P, Ripke S, Xiong L, Jalilzadeh S, et al. Genome-wide association study of restless legs syndrome identifies common variants in three genomic regions. Nat Genet 2007;39:10001006.

15. Kang SG, Lee HJ, Choi JE, Park JH, Lee SS, Han C, et al. Possible association between $\mathrm{G}$-protein $\beta 3$ subunit C825T polymorphism and antipsychotic-induced restless legs syndrome in schizophrenia. Acta Neuropsychiatrica 2007;19:351-356.

16. Kang SG, Lee HJ, Choi JE, Park YM, Park JH, Han C, et al. Association study between antipsychotics- induced restless legs syndrome and polymorphisms of dopamine D1, D2, D3, and D4 receptor genes in schizophrenia. Neuropsychobiology 2008;57:49-54

17. Kang SG, Park YM, Choi JE, Lim SW, Lee HJ, Lee SH, et al. Association study between antipsychotic-induced restless legs syndrome and polymorphisms of monoamine oxidase genes in schizophrenia. Hum Psychopharmacol 2010;25:397-403.

18. Cho CH, Kang SG, Choi JE, Park YM, Lee HJ, Kim L. Association between Antipsychotics-Induced Restless Legs Syndrome and Tyrosine Hydroxylase Gene Polymorphism. Psychiatry Investig 2009;6:211-215.

19. Kang SG, Lee HJ, Park YM, Yang HJ, Song HM, Lee YJ, et al. The BTBD9 gene may be associated with antipsychotic-induced restless legs syndrome in schizophrenia. Hum Psychopharmacol 2013;28:117123.

20. Jung JS, Lee HJ, Cho CH, Kang SG, Yoon HK, Park YM, et al. Association between restless legs syndrome and CLOCK and NPAS2 gene polymorphisms in schizophrenia. Chronobiol Int 2014;31:838-844.

21. Kang SG, Lee HJ, Lee SH, Kim L. MEIS1, a Promising Candidate Gene, Is Not Associated with the Core Symptoms of Antipsychotic-Induced Restless Legs Syndrome in Korean Schizophrenia Patients. Psychiatry Investig 2015;12:263-267.

22. Han OS, Hong JP. Structured Clinical Interview for DSM-IV Axis I Disorder-Korean Version. Seoul: Hana Medical Publishing; 2000.

23. American Psychiatric Association. Practice Guidelines for the Treatment of Patients with Schizophrenia. Washington, DC: American Psychiatric Press; 1997.

24. Bazire S. Psychotropic Drug Directory. The Professionals' Pocket Hand- book and Aide Memoire. Salisbury, UK: Fivepin; 2005.

25. Hales RE, Yudofski SC. Textbook of Clinical Psychiatry, Fourth Ed. Washington, DC: American Psychiatric Publishing; 2002.

26. Inagaki A, Inada T, Fujii Y, Yagi G, Yoshio T, Nakamura H, et al. Dose Equivalence of Psychotic Drugs. Tokyo: Seiwa Press; 1999.

27. Woods SW. Chlorpromazine equivalent doses for the newer atypical antipsychotics. J Clin Psychiatry 2003;64:663-667.

28. Allen RP, Picchietti D, Hening WA, Trenkwalder C, Walters AS, Montplaisi J. Restless legs syndrome: diagnostic criteria, special considerations, and epidemiology. A report from the restless leg syndrome diagnosis and epidemiology workshop at the National Institute of Health. Sleep Med 2003;4:101-119.

29. Walters AS, LeBrocq C, Dhar A, Hening W, Rosen R, Allen RP, et al. Validation of the International Restless Legs Syndrome Study Group rating scale for restless legs syndrome. Sleep Med 2003;4:121-132.

30. Barnes TR. A rating scale for drug-induced akathisia. Br J Psychiatry 1989:672-676

31. Lin CH, Chen ML, Wu VC, Li WY, Sy HN, Wu SL, et al. Association of candidate genetic variants with restless legs syndrome in end stage renal disease: a multicenter case-control study in Taiwan. Eur J Neurol 2014; 21:492-498.

32. Klingaman EA, Palmer-Bacon J, Bennett ME, Rowland LM. Sleep disorders among people with schizophrenia: emerging research. Curr Psychiatry Rep 2015;17:79.

33. Kemlink D, Polo O, Frauscher B, Gschliesser V, Hogl B, Poewe W, et al. Replication of restless legs syndrome loci in three European populations. J Med Genet 2009;46:315-318.

34. Moore H 4th, Winkelmann J, Lin L, Finn L, Peppard P Mignot E. Periodic leg movements during sleep are associated with polymorphisms in BTBD9, TOX3/BC034767, MEIS1, MAP2K5/SKOR1, and PTPRD. Sleep 2014;37:1535-1542.

35. Yang Q, Li L, Chen Q, Foldvary-Schaefer N, Ondo WG, Wang QK. Association studies of variants in MEIS1, BTBD9, and MAP2K5/SKOR1 with restless legs syndrome in a US population. Sleep Med 2011;12:800804.

36. Zhou G, Bao ZQ, Dixon JE. Components of a new human protein kinase signal transduction pathway. J Biol Chem 1995;270:12665-12669.

37. Dinev D, Jordan BW, Neufeld B, Lee JD, Lindemann D, Rapp UR, et al. Extracellular signal regulated kinase 5 (ERK5) is required for the differentiation of muscle cells. EMBO Rep 2001;2:829-834.

38. Cavanaugh JE, Jaumotte JD, Lakoski JM, Zigmond MJ. Neuroprotective role of ERK1/2 and ERK5 in a dopaminergic cell line under basal conditions and in response to oxidative stress. J Neurosci Res 2006;84:13671375.

39. Hening WA. Current guidelines and standards of practice for restless legs syndrome. Am J Med 2007;120(1 Suppl 1):S22-S27.

40. Mignot E. A step forward for restless legs syndrome. Nat Genet 2007; 39:938-939.

41. Winkelmann J, Czamara D, Schormair B, Knauf F, Schulte EC, Trenkwalder $\mathrm{C}$, et al. Genome-wide association study identifies novel restless legs syndrome susceptibility loci on 2p14 and 16q12.1. PLoS Genet 2011;7:e1002171.

42. Vilarino-Guell C, Farrer MJ, Lin SC. A genetic risk factor for periodic limb movements in sleep. N Engl J Med 2008;358:425-427.

43. Kim MK, Cho YW, Shin WC, Cho JW, Shon YM, Kim JH, et al. Association of restless legs syndrome variants in Korean patients with restless legs syndrome. Sleep 2013;36:1787-1791. 